\title{
言語測度に基づいた最適スーパバイザの強化学習*
}

\author{
谷口 和隆 ${ }^{\dagger} \cdot$ 山㟝 達志 $\ddagger$ 潮 俊光 ${ }^{\dagger}$
}

\section{Reinforcement Learning of Optimal Supervisor Based on Language Measure*}

\author{
Kazutaka TANIGUCHI ${ }^{\dagger}$, Tatsushi YAMASAKI ${ }^{\ddagger}$ and Toshimitsu UshIO ${ }^{\dagger}$
}

\begin{abstract}
Recently, Wang and Ray introduced a signed measure for formal languages, called a language measure, to evaluate performance of strings generated by discrete event systems and a synthesis method of an optimal supervisor based on the language measure has been studied. In order to apply the method, exact information about a language measure of a controlled discrete event system is needed. From the practical point of view, it is not always possible to know the information a priori. In such a situation, a learning-based approach is useful to obtain an optimal supervisor with respect to the language measure.

This paper considers a synthesis method of an optimal supervisor with respect to a language measure. First, we clarify the relationship between the Bellman equation in reinforcement learning and performance of the language generated by the controlled discrete event systems. Next, using the relationship, we propose a learning method of the optimal supervisor where costs of disabling events are taken into consideration. Finally, by computer simulation, we illustrate an efficiency of the proposed method.
\end{abstract}

\section{1.はじめに}

離散事象システム $[1]$ に対する論理的な制御法として, スーパバイザ制御がある $[2,3]$. スーパバイザ制御では, 制御仕様を満足するという制約のもとに，システムの生 成言語が最大になるという意味で最適な制御パターンを 指定する。これは，できる限りシステム本来の挙動を制 限せずに多くの事象の生起を許容することが望ましいと いう考え方に基づいている。このとき，あらかじめ制御 対象および制御仕様が，厳密に形式言語あるいはオート マトンで記述されている必要がある。しかし，多くの場 合, 要求される仕様を正確な形式言語で表現することは 簡単ではない。また，スーパバイザ制御は論理的な制御

* 原稿受付 2005 年 3 月 14 日

†大阪大学大学院基礎工学研究科 Graduate School of Engineering Science, Osaka University; 1-3 Machikaneyama-cho, Toyonaka city, Osaka 560-8531, JAPAN

‡関西学院大学 理工学部 School of Science and Technology, Kwansei Gakuin University; 2-1 Gakuen, Sanda city, Hyogo 669-1337, JAPAN

Key Words: language measure, supervisory control, reinforcement learning, discrete event system.
の枠組みであるため，望ましくない状態に至らないよう に制御することはできるが，事象の生起や禁止のための コストは考慮していない.これに関して, コストを考慮 した最適スーパバイザ制御についての研究もなされてい る. Braveらは，望ましい状態にシステムを維持するた めのコストに関しての最適スーパバイザ制御について研 究している [8]. Kumarらは, 事象の禁止コストと到達 した状態に関する報酬に関する最適スーパバイザ制御 について考察している [9]. Sengupta らは, 事象の生起 と禁止のコストを考慮し, 最悪ケースでのコストを最小 とする最適スーパバイザの設計法を提案している $[11]$. さらに，Marchandらは，部分観測の場合に拡張してい る $[10]$.

最近, Rayらによって言語測度とよばれる形式言語に 対する符号付の実測度の概念が導入された $[4,5]$.この 言語測度を用いることによって, 離散事象システムを定 量的に評価することができる．既知の環境に対する言語 測度に基づく最適スーパバイザの設計法が提案されてお り [6], 状態の価值が既知の場合に, ロボットの行動選 択の学習を言語測度に基づき行う手法も提案されてい る $[7]$.

いっぽう, 近年注目されている学習手法に強化学習が 
あるが, 多くの強化学習では, 学習者の受け取る割引報 酬の総和が最大となるという意味で最適な行動政策を, 試行錯誤を通じて学習していく.

山㟝らは，スーパバイザの設計に強化学習を用いて， 最適な制御パターンを求めている $[12-14]$. しかし, 最 適性の扱いについて, スーパバイザ制御の基礎となる形 式言語理論との関連が明らかではなかった. 本論文では, Bellman 方程式の状態価值関数が言語測度におけるパ フォーマンスベクトルと一致することを示し, 言語測度 に基づいて最適となるスーパバイザを強化学習によって 設計する方法を提案する. また提案手法では, 従来の最 適スーパバイザ制御と異なり，事象のコストが正確にわ からない場合や, 制御仕様の形式言語による厳密な記述 ができない場合にも適用可能である，また，それらが変 化する場合にも学習を続けることにより適応できる. 提 案手法を食事をする哲学者の問題に適用することにより, 最適なスーパバイザが獲得できることを示す.

以下，2.ではスーパバイザ制御と言語測度について述 ベる．3.ではスーパバイザ制御の数理モデルを示し，言 語測度との関係を明らかにする.4. では本論文で提案す るスーパバイザ学習のアルゴリズムを示す. 5. では計算 機実験により提案アルゴリズムの有効性を示す．最後に 6. でまとめと今後の課題を述べる.

\section{2. スーパバイザ制御と言語測度}

本論文では事象は, 可制御な事象と不可制御な事象に わけることができると仮定する。制御対象となる離散事 象システムに対して制御仕様を満たすようにスーパバイ ザがシステムの可制御な事象の生起を許容または禁止 する $[2,3]$. スーパバイザ制御の枠組みは，Fig. 1 で表さ れる.

制御の基本的な流れは，以下の通りである.

（1）スーパバイザが，生起を禁止する事象の集合 (生起 禁止パターン) を離散事象システムに提示する。

(2) 離散事象システムは生起禁止パターン以外から事 象を選択し，新たな状態に遷移する。

(3) スーパバイザは, 離散事象システムの生起事象を 観測する。

離散事象システム $G$ のモデルとして, ここではオー トマトン表現 $G=\left(X, \Sigma, \delta, x_{1}, X_{m}\right)$ を用いる。たた し, $X$ は状態の集合, $\Sigma$ は事象の集合, $\delta: \Sigma \times X \rightarrow X$ は状態遷移関数, $x_{1} \in X$ は初期状態, $X_{m} \subseteq X$ は目標 状態を表す. 空事象 $\epsilon$ を含み, $\Sigma$ の要素からなるすべ

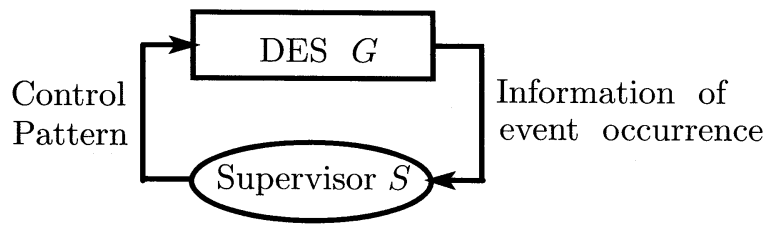

Fig. 1 Discrete event system controlled by the supervisor
ての事象列の集合を $\Sigma^{*}$ とおき, $\delta を \delta: X \times \Sigma^{*} \rightarrow X$ に拡張する。 $\Sigma^{c}$ を可制御な事象の集合， $\Sigma^{u c}$ を不可制 御な事象の集合とすると, $\Sigma=\Sigma^{c} \cup \Sigma^{u c}, \Sigma^{c} \cap \Sigma^{u c}=\emptyset$ である. 集合の要素数を $|\cdot|$ で表し, $G$ では $|X|=n$, $|\Sigma|=m$ とする. $\mathcal{I}=\{1,2, \ldots, n\}$ はインデックス集 合である. 状態 $x_{i}$ から状態 $x_{k}$ に遷移する事象のイ ンデックス集合を $\sigma_{i}^{k}=\left\{j \mid \delta\left(x_{i}, \sigma_{j}\right)=x_{k}\right\}$ で定義す る. 状態 $x_{i}$ で遷移が定義されている事象のインデック ス集合を $\hat{\sigma}_{i}=\left\{j \mid \delta\left(x_{i}, \sigma_{j}\right)\right.$ is defined $\}$ で定義する。ま た, 状態 $x_{i}$ から始まり, $G$ によって生成される言語を, $L\left(G, x_{i}\right)=\left\{s \in \Sigma^{*} \mid \delta\left(x_{i}, s\right) \in X\right\}$ によって定義する.

Ramadge と Wonham による元々のスーパバイザ制 御の枠組みは論理的なものであり, 最大可制御部分言 語の設計が重要な関心であった。本論文では, Ray ら によって拡張されたスーパバイザ制御の枠組みを考え る.ここでは事象や状態に定量的な指標を割り当て, それらを用いてシステムの生成言語に対し, 符号付の 実測度を与えることでスーパバイザを評価する $[4,5]$. $X_{m}$ を可到達が望ましい状態の集合 $X_{m}^{+}$と, 可到達が 望ましくない状態の集合 $X_{m}^{-}$に分割する.すなわち, $X_{m}=X_{m}^{+} \cup X_{m}^{-}, X_{m}^{+} \cap X_{m}^{-}=\emptyset$ であ. 状態に対する 評価值として，任意の $i \in \mathcal{I} に$ 対し特性関数 $y: X \rightarrow \Re を$ 以下のように定義する。

$$
y\left(x_{i}\right)=y_{i} \in \begin{cases}\{0\} & \text { if } x_{i} \notin X_{m} \\ (0,1] & \text { if } x_{i} \in X_{m}^{+} \\ {[-1,0)} & \text { if } x_{i} \in X_{m}^{-}\end{cases}
$$

$Y=\left[y_{1}, y_{2}, \ldots, y_{n}\right]^{\mathrm{T}}$ を特性べクトルとよぶ.

任意の $x_{i} \in X, \sigma_{j} \in \Sigma, s \in \Sigma^{*}$ に対して以下の 3 条件 を満たす関数 $\tilde{\pi}: \Sigma^{*} \times X \rightarrow[0,1]$ を $G$ の事象コストと 定義する.

(1) $\tilde{\pi}\left[\sigma_{j} \mid x_{i}\right]=\tilde{\pi}_{i j} \in[0,1), \quad \forall i \in \mathcal{I}, \quad \sum_{j} \tilde{\pi}_{i j}<1$

(2) $\tilde{\pi}\left[\sigma_{j} \mid x_{i}\right]=0$ if $\delta\left(x_{i}, \sigma_{j}\right)$ is undefined

(3) $\tilde{\pi}\left[\sigma_{j} s \mid x_{i}\right]=\tilde{\pi}\left[\sigma_{j} \mid x_{i}\right] \tilde{\pi}\left[s \mid \delta\left(x_{i}, \sigma_{j}\right)\right]$

スーパバイザ $S$ にって状態 $x_{i}$ で可制御事象 $\sigma_{j} \in \Sigma^{c}$ の生起を指定するアクションを次のようにおく.

$$
d_{i j}^{S}= \begin{cases}1 & \text { if } \sigma_{j} \text { の生起を禁止 } \\ 0 & \text { otherwise }\end{cases}
$$

スーパバイザ $S$ にって制御されたシステム $S / G$ の 状態遷移コスト $\pi^{S}: X \times X \rightarrow[0,1)$ を以下のように定義 する。

$$
\begin{aligned}
& \pi^{S}\left[x_{k} \mid x_{i}\right]=\pi_{i k}^{S} \\
& = \begin{cases}\sum_{j \in \sigma_{i}^{k}-d_{i}^{S}} \tilde{\pi}\left[\sigma_{j} \mid x_{i}\right] & \text { if } \sigma_{i}^{k}-d_{i}^{S} \neq \emptyset \\
0 & \text { otherwise }\end{cases}
\end{aligned}
$$

ただし,$d_{i}^{S}=\left\{j \mid d_{i j}^{S}=1\right\}$ は状態 $x_{i}$ で生起が禁止され た事象のインデックスの集合を表し, 生起禁止パターン 
とよぶ. $D^{S}\left(x_{i}\right)$ により, 状態 $x_{i}$ の生起禁止パターンの 集合を表す.この $(i, k)$ 要素が $\pi_{i k}^{S}$ となる行列を $\Pi^{S}$ とお く. 以下, この行列を $\Pi^{S}$ 行列とよぶ.

状態 $x_{i}$ に扔いて可制御事象 $\sigma_{j} \in \Sigma^{c}$ が生起して状態 $x_{k}$ に遷移することを禁止することで生じるコストを $c_{i j}^{k}$ とおく. $x_{k}$ が文脈から明らかなときは $c_{i j}$ と略記する. $n \times m$ 行列 $C=\left[c_{i j}\right]$ を生起禁止コス卜行列とよぶ. 状態 $x_{i}$ で事象の生起を禁止することによるスーパバイザ $S$ の 生起禁止コスト特性を

$$
\xi_{i}^{S}=\xi_{i}\left(x_{i}, d_{i}^{S}\right)=\sum_{j \in d_{i}^{S}} c_{i j}
$$

と扔く、スーパバイザ $S$ の生起禁止コスト特性ベクトル を $\xi^{S}=\left[\xi_{1}^{S}, \xi_{2}^{S}, \ldots, \xi_{n}^{S}\right]^{\mathrm{T}}$ と定義する. 生起禁止パ夕一 ンの与え方によって，Yは変化し，スーパバイザ $S$ のも とでの修正特性べクトルを

$$
Y^{S}=\left[y_{1}^{S}, y_{2}^{S}, \ldots, y_{n}^{S}\right]^{\mathrm{T}}=Y-\xi^{S}
$$

と定義する，ただし， $y_{i}^{S}=y_{i}-\xi_{i}^{S}$ である.

このとき, 制御されたシステム $S / G$ の言語測度べク トル $\mu^{S}$ は,

$$
\mu^{S}=\left[\mu_{1}^{S}, \mu_{2}^{S}, \ldots, \mu_{n}^{S}\right]^{\mathrm{T}}=\left[I-\Pi^{S}\right]^{-1} Y^{S}
$$

で与えられ，パフォーマンスベクトルとよばれる。ただ

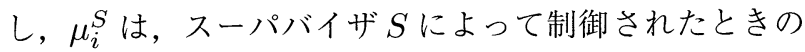
$L\left(G, x_{i}\right)$ の言語測度であり, 状態 $x_{i}$ におけるパフォーマ ンスを表す。言語測度を用いることにより，スーパバイ ザについて，従来の最大可制御言語に基づく定性的な評 価でなく，定量的な評価が可能となる.

\section{3. 言語測度と Bellman 方程式}

制御されたシステム $S / G$ に対し，以下の Bellman方 程式が成り立つ.

$$
\begin{aligned}
V^{d}\left(x_{i}\right)= & \sum_{x_{k} \in X} P\left(x_{i}, d_{i}^{S}, x_{k}\right) \\
& \times\left[r^{*}\left(x_{i}, d_{i}^{S}, x_{k}\right)+\gamma V^{d}\left(x_{k}\right)\right]
\end{aligned}
$$

ここで, $P\left(x_{i}, d_{i}^{S}, x_{k}\right)$ は状態 $x_{i} \in X$ でスーパバイザ $S$ が生起禁止パターン $d_{i}^{S} \in D^{S}\left(x_{i}\right)$ を選択したときに状態 $x_{k} \in X$ に遷移する確率, $V^{d}\left(x_{i}\right)$ は状態 $x_{i}$ での期待収益 (以後に獲得する割引報酬の総和の期待值), $r^{*}\left(x_{i}, d_{i}^{S}, x_{k}\right)$ は状態 $x_{i}$ に扔いて生起禁止パターン $d_{i}^{S}$ が選択され， $x_{k}$ への遷移が起こった場合に受け取る報酬の期待值， $\gamma$ は 報酬の割引率を表す. $V^{d}\left(x_{i}\right)$ は状態価值関数とよばれ る. Gは $S$ にって与えられた生起禁止パターン以外か ら生起事象を選択することから，

$$
P\left(x_{i}, d_{i}^{S}, x_{k}\right)=\sum_{j \notin d_{i}^{S}} P_{1}\left(x_{i}, d_{i}^{S}, \sigma_{j}\right) P_{2}\left(x_{i}, \sigma_{j}, x_{k}\right)
$$

が成り立つ.ただし, $P_{1}\left(x_{i}, d_{i}^{S}, \sigma_{j}\right)$ は状態 $x_{i}$ で, スー パバイザが生起禁止パターン $d_{i}^{S}$ を選択したとき, 事 象 $\sigma_{j}\left(j \notin d_{i}^{S}\right)$ が制御対象 $G$ によって選択される確率, $P_{2}\left(x_{i}, \sigma_{j}, x_{k}\right)$ は状態 $x_{i}$ で事象 $\sigma_{j}\left(j \in \sigma_{i}^{k}\right)$ が生起したと き, 状態 $x_{k}$ に遷移する確率を表す.

提案手法に扔いては， $S / G$ に対して以下の仮定を設 ける。

仮定 1：各状態 $x_{i} \in X$ と事象 $\sigma \in \Sigma \cup\{\epsilon\}$ につい て，Gの事象の選ばれやすさを表すパラメータとして, $\tilde{\pi}^{*}\left(x_{i}, \sigma\right)$ を導入する.

このとき，

$$
P_{1}\left(x_{i}, d_{i}^{S}, \sigma\right)=\frac{\tilde{\pi}^{*}\left(x_{i}, \sigma\right)}{\sum_{l \notin d_{i}^{S}} \tilde{\pi}^{*}\left(x_{i}, \sigma_{l}\right)+\tilde{\pi}^{*}\left(x_{i}, \epsilon\right)}
$$

とする.ここで,

$$
\begin{aligned}
\tilde{\pi}^{*}\left(x_{i}, \sigma_{j}\right) & \in[0,1), \tilde{\pi}^{*}\left(x_{i}, \epsilon\right)>0 \\
\tilde{\pi}^{*}\left(x_{i}, \sigma_{j}\right) & =0 \text { if } \delta\left(x_{i}, \sigma_{j}\right) \text { is undefined } \\
\sum_{j \in \hat{\sigma}_{i}} \tilde{\pi}^{*}\left(x_{i}, \sigma_{j}\right) & +\tilde{\pi}^{*}\left(x_{i}, \epsilon\right)=1
\end{aligned}
$$

という関係が成り立っているとする。本論文では, 空事 象 $\epsilon$ は, どの事象も生起せずに現在の状態にとどまり, 報酬を得ることなしに時間のみが1ステップ進むことを 意味するとする。そのため, $\tilde{\pi}^{*}\left(x_{i}, \epsilon\right)$ が大きいと，その 状態に長くとどまる可能性が高くなる，さらに，報酬の 割引率 $\gamma$ が次のような構造を持つとする.

$$
\gamma=\gamma\left(x_{i}, d_{i}^{S}\right)=\sum_{l \notin d_{i}^{S}} \tilde{\pi}^{*}\left(x_{i}, \sigma_{l}\right)+\tilde{\pi}^{*}\left(x_{i}, \epsilon\right)
$$

これより， $\gamma \in(0,1]$ である.

また, $S / G$ に対して, $\pi^{* S}: X \times X \rightarrow[0,1)$ を以下の ように定義する。

$$
=\left\{\begin{array}{l}
\pi_{j \in \sigma_{i}^{k}-d_{i}^{S}}^{* S}\left(x_{k} \mid x_{i}\right)=\pi_{i k}^{* S} \\
0 \quad \text { if } P_{i}^{k}-d_{i}^{S} \neq \emptyset \\
0 \quad \text { otherwise }
\end{array}\right.
$$

ここで，(9), (13)式より, 次式が得られる.

$$
\pi_{i k}^{* S}= \begin{cases}\sum_{j \in \sigma_{i}^{k}-d_{i}^{S}} \tilde{\pi}^{*}\left(x_{i}, \sigma_{j}\right) & \text { if } \sigma_{i}^{k}-d_{i}^{S} \neq \emptyset \\ 0 & \text { otherwise }\end{cases}
$$

$(i, k)$ 要素が $\pi_{i k}^{* S}$ となる行列を $\Pi^{* S}$ とおき, 以下, $\Pi^{* S}$ 行列とよぶ.

仮定 2：報酬 $r^{*}\left(x_{i}, d_{i}^{S}, x_{k}\right)$ について,

$$
r^{*}\left(x_{i}, d_{i}^{S}, x_{k}\right)=r_{1}^{*}\left(x_{i}, d_{i}^{S}\right)+r_{2}^{*}\left(x_{i}, \sigma_{j}, x_{k}\right)
$$


という構造を持つとする。ここで, $r_{1}^{*}\left(x_{i}, d_{i}^{S}\right)$ は状態 $x_{i}$ で生起禁止パターン $d_{i}^{S}$ を選択したときの報酬の期待値, $r_{2}^{*}\left(x_{i}, \sigma_{j}, x_{k}\right)$ は状態 $x_{i}$ で事象 $\sigma_{j}$ が生起され, 状態 $x_{k}$ に 遷移したときの報酬の期待值を表す。

つぎに, Bellman方程式における状態価値関数が Ray らの提案する言語測度に一致することを示す.

Ray らの定義 [4]に従うとき, 受け取る報酬は生起禁止 パターンの与え方と現在の状態の評価值に依存し，事象 の生起に伴う報酬は考慮しないので, $r_{2}^{*}\left(x_{i}, \sigma_{j}, x_{k}\right)=0$ とおける。

また, $r_{1}^{*}\left(x_{i}, d_{i}^{S}\right)$ は次のような構造を持つとする.

$$
r_{1}^{*}\left(x_{i}, d_{i}^{S}\right)=y\left(x_{i}\right)-\xi\left(x_{i}, d_{i}^{S}\right)
$$

上式より報酬 $r_{1}^{*}$ は状態の特性関数と生起禁止コストの 差より決まるため, 修正特性べクトルを表す(5)式の $y_{i}^{S}$ に対応するものととらえることができる。また本論文で は，学習においては $y$ と $\xi$ は陽には現れず，報酬として まとめて扱われる。

ベクトル $R$ を以下のように定義する.

$$
R=\left[r_{1}^{*}\left(x_{1}, d_{1}^{S}\right), r_{1}^{*}\left(x_{2}, d_{2}^{S}\right), \ldots, r_{1}^{*}\left(x_{n}, d_{n}^{S}\right)\right]^{\mathrm{T}}
$$

以上より, 状態の遷移が決定的の場合，(7)式は,

$$
V^{d}\left(x_{i}\right)=r_{1}^{*}\left(x_{i}, d_{i}^{S}\right)+\sum_{x_{k} \in X} \pi_{i k}^{* S} V^{d}\left(x_{k}\right)
$$

となる.ここで，

$$
V=\left[V^{d}\left(x_{1}\right), V^{d}\left(x_{2}\right), \ldots, V^{d}\left(x_{n}\right)\right]^{\mathrm{T}}
$$

とすると, 以下の式が成り立つ.

$$
V=R+\Pi^{* S} V
$$

これより，

$$
V=\left(I-\Pi^{* S}\right)^{-1} R
$$

という関係が得られる。ここで $\Pi^{* S}=\Pi^{S}, R=Y$ であ るから, Bellman 方程式に扔ける状態価值関数 $V^{d}$ のべ クトル $V$ は (6) 式で定義したパフォーマンスベクトル $\mu^{S}$ と一致することが示された。

Rayらの提案する言語測度は, システムの生成言語に 基づく定量的な性能指標であるが，これを Bellman 方 程式における状態価值関数として解秎できることがわか る。そのため, 直観的には言語測度は, 事象の制御コス トと状態の評価值に関する期待報酬を与えるものといえ る. Bellman方程式の状態価值関数として言語測度を求 めることができ，こうして得られた言語測度に基づく最 適スーパバイザのもとでは, 期待報酬に関して最適なシ ステムの振る舞いが得られる。

\section{4. スーパバイザ学習のアルゴリズム}

3.の結果より, Bellman 方程式に基づいてパフォーマ ンスベクトルを計算する手法を提案する。提案手法では, 言語測度における, 状態の特性関数, 事象コスト, 生起禁 止コストが未知の場合に, パフォーマンスベクトルを最 大にする生起禁止パターンを求めるために，Q-learning に基づく更新式による学習を行う。これらの值は, 実環 境に扔いては, 学習者側からは未知であったり, ノイズ が含まれていたりして，実際に観測することのみを通じ て得られる場合がある。ある時刻において状態が $x_{i} \in X$ であるとする.ここで, 学習者たるスーパバイザ $S$ は生 起禁止パターン $d_{i}^{S} \in D^{S}\left(x_{i}\right)$ として, 生起を禁止する事 象の集合を $G$ に提示する。これにより, 離散事象システ ムの状態に対して制御パターンを決定するという, 状態 フィードバック制御となる。

(7) 式に対応する, $Q$ 值に関する Bellman 最適方程 式は,

$$
\begin{aligned}
& Q^{*}\left(x_{i}, d_{i}^{S}\right)=\sum_{x_{k} \in X} P\left(x_{i}, d_{i}^{S}, x_{k}\right) \\
& \quad \times\left[r^{*}\left(x_{i}, d_{i}^{S}, x_{k}\right)+\gamma \max _{d_{k}^{S} \in D^{S}\left(x_{k}\right)} Q^{*}\left(x_{k}, d_{k}^{S}\right)\right]
\end{aligned}
$$

となる $[12]$. ただし, $Q^{*}\left(x_{i}, d_{i}^{S}\right)$ は, 状態 $x_{i} \in X$ で生起 禁止パターン $d_{i}^{S} \in D^{S}\left(x_{i}\right)$ を選択し, 以後は各状態で最 大の $Q$ 值を持つ生起禁止パターンを選択するときの期待 収益である。 ここで, 仮定 1,2 と状態遷移が決定的であ ると仮定することにより, Bellman 最適方程式は次のよ うに変形できる。

$$
\begin{gathered}
\begin{aligned}
Q^{*}\left(x_{i}, d_{i}^{S}\right) & =r_{1}^{*}\left(x_{i}, d_{i}^{S}\right) \\
& +\sum_{j \notin d_{i}^{S}} \tilde{\pi}^{*}\left(x_{i}, \sigma_{j}\right) V^{*}\left(\delta\left(x_{i}, \sigma_{j}\right)\right)
\end{aligned} \\
\text { ただし, 状態 } x_{k}=\delta\left(x_{i}, \sigma_{j}\right) \in X \text { に対し, } \\
V^{*}\left(x_{k}\right)=\max _{d_{k}^{S} \in D^{S}\left(x_{k}\right)} Q^{*}\left(x_{k}, d_{k}^{S}\right)
\end{gathered}
$$

である.このとき, 制御対象 $G$ では, 生起が禁止されてい ない事象の中から (9) 式の確率で事象 $\sigma=\sigma_{j}\left(j \in \hat{\sigma}_{i}-d_{i}^{S}\right)$ が生起する，Gでの事象の生起により, 状態 $x_{i}$ が $x_{k} に$ 遷移し, 報酬 $r$ を獲得する.ただし, 空事象 $\sigma=\epsilon か ゙$ 生 じた場合は何の事象も生起せずにその状態にとどまり, 報酬を受け取らずに時間のみが 1 ステップ進むとする。 (24) 式より， $Q^{*}$ は $r_{1}^{*}, \tilde{\pi}^{*}$ を用いて間接的に求めること ができる、そこで，本論文では，

$$
r_{1}^{\prime}\left(x_{i}, d_{i}^{S}\right) \leftarrow r_{1}^{\prime}\left(x_{i}, d_{i}^{S}\right)+\alpha\left[r-r_{1}^{\prime}\left(x_{i}, d_{i}^{S}\right)\right]
$$




$$
\tilde{\pi}^{\prime}\left(x_{i}, \sigma^{\prime}\right) \leftarrow\left\{\begin{array}{c}
(1-\beta) \tilde{\pi}^{\prime}\left(x_{i}, \sigma^{\prime}\right) \\
\text { if } \quad \sigma^{\prime} \neq \sigma \\
\tilde{\pi}^{\prime}\left(x_{i}, \sigma^{\prime}\right)+\beta\left[\sum_{m \in \hat{\sigma}_{i}-d_{i}^{S}} \tilde{\pi}^{\prime}\left(x_{i}, \sigma_{m}\right)\right. \\
\left.+\tilde{\pi}^{\prime}\left(x_{i}, \epsilon\right)-\tilde{\pi}^{\prime}\left(x_{i}, \sigma^{\prime}\right)\right] \\
\text { if } \sigma^{\prime}=\sigma
\end{array}\right.
$$

として, $r_{1}^{*}, \tilde{\pi}^{*}$ を推定する.ここで, $r_{1}^{\prime}, \tilde{\pi}^{\prime}$ はそれぞれ $r_{1}^{*}, \tilde{\pi}^{*}$ の推定値, $\alpha, \beta$ は学習率である. なお, 空事象 $\epsilon$ が生起した場合は, 報酬を受け取らないため, (26) 式に よる更新は行わない. $r_{1}^{\prime}, \tilde{\pi}^{\prime}$ 用いて, 実際に選択した生 起禁止パターン $d_{i}^{S}$ で許可された事象をすべて禁止して いる生起禁止パターン以外に対して同時に $Q$ 值の更新を 行うことができる.すなわち, $\left(\hat{\sigma}_{i}-d_{i}^{S^{\prime}}\right) \cap\left(\hat{\sigma}_{i}-d_{i}^{S}\right) \neq \emptyset$ を満たす，すべての $d_{i}^{S^{\prime}} \in D^{S}\left(x_{i}\right)$ に対して，

$$
\begin{aligned}
Q\left(x_{i}, d_{i}^{S^{\prime}}\right) & \leftarrow r_{1}^{\prime}\left(x_{i}, d_{i}^{S^{\prime}}\right) \\
& +\sum_{j \in \hat{\sigma}_{i}-d_{i}^{S^{\prime}}} \tilde{\pi}^{\prime}\left(x_{i}, \sigma_{j}\right) V^{\prime}\left(\delta\left(x_{i}, \sigma_{j}\right)\right)
\end{aligned}
$$

として，間接的に $Q$ 值を推定する.ただし，状態 $x_{k}=$ $\delta\left(x_{i}, \sigma_{j}\right) \in X$ に対し,

$$
V^{\prime}\left(x_{k}\right)=\max _{d_{k}^{S} \in D^{S}\left(x_{k}\right)} Q^{*}\left(x_{k}, d_{k}^{S}\right)
$$

である。

状態 $x_{i}$ で事象 $\sigma_{j}$ を禁止する確率を $\tilde{d}_{i j} \in[0,1]$ で表す. $\tilde{d}_{i j}$ から生起禁止パターンを構成する. 状態 $x_{i}$ で最大の $Q$ 值を与える生起禁止パターンを $\hat{d}_{i}^{S}$ とおく.

$$
\hat{d}_{i}^{S}=\arg \max _{d_{i}^{S} \in D^{S}\left(x_{i}\right)} Q\left(x_{i}, d_{i}^{S}\right) \in D^{S}\left(x_{i}\right)
$$

$\hat{d}_{i}^{S}$ を用いて $\tilde{d}_{i j}$ を以下のように更新する.

$$
\tilde{d}_{i j} \leftarrow\left\{\begin{array}{lll}
\tilde{d}_{i j}+\lambda\left(1-\tilde{d}_{i j}\right) & \text { if } & j \in \hat{d}_{i}^{S} \\
\tilde{d}_{i j}+\lambda\left(0-\tilde{d}_{i j}\right) & \text { if } & j \notin \hat{d}_{i}^{S}
\end{array}\right.
$$

ただし，入は学習率である。(31) 式は $Q$ 值を最大にする 生起禁止パターンに属する事象は禁止する確率を増やし, そうでない事象は減らすことで $Q$ 值が最大な生起禁止パ ターンを学習する。また，生起禁止パターンを $\tilde{d}_{i j}$ に基 づき決定することにより, 最適と考えられる生起禁止パ ターンおよびその周辺をより高い確率で選択しつつ学習 を進める。

以上より，スーパバイザの学習アルゴリズムは Fig. 2 のようになる.

\section{5. シミュレーション}

文献 [4] で例題として取り上げられた 2 人の食事をす る哲学者の問題を考える。この問題の離散事象システ ムは, Fig. 3のオートマトンで表される.ここで, 各哲
(1) Initialize $r_{1}^{\prime}\left(x_{i}, d_{i}^{S}\right)$ and $\tilde{\pi}^{\prime}\left(x_{i}, \sigma\right)$ at each state.

(2) Calculate the initial $Q$ value at each state by Eq. (24).

(3) Repeat (for each episode):

(a) $x_{i} \leftarrow$ initial state $x_{1}$.

(b) Repeat until $x_{i}$ is a terminal state (for each step of episode) :

i. Assign a control pattern $d_{i}^{S} \in D^{S}\left(x_{i}\right)$ based on $\tilde{d}_{i j}$.

ii. Observe the occurrence of event $\sigma$ and state transition $x_{i} \stackrel{\sigma}{\rightarrow} x_{k}$ in the DES $G$.

iii. Acquire a reward $r$.

iv. Update $r_{1}^{\prime}\left(x_{i}, d_{i}^{S}\right)$ and $\tilde{\pi}^{\prime}\left(x_{i}, \sigma\right)$ by Eqs. (26) and (27), respectively.

v. Update the $Q$ values for all $d_{i}^{S^{\prime}} \in$ $D^{S}\left(x_{i}\right)$ s.t. $\left(\hat{\sigma}_{i}-d_{i}^{S^{\prime}}\right) \cap\left(\hat{\sigma}_{i}-d_{i}^{S}\right) \neq \emptyset$ by Eq. (28).

vi. Calculate $\hat{d}_{i}^{S}$ by Eq. (30) and update the probability $\tilde{d}_{i j}$ by Eq. (31).

vii. $x_{i} \leftarrow x_{k}$.

Fig. 2 Proposed algorithm

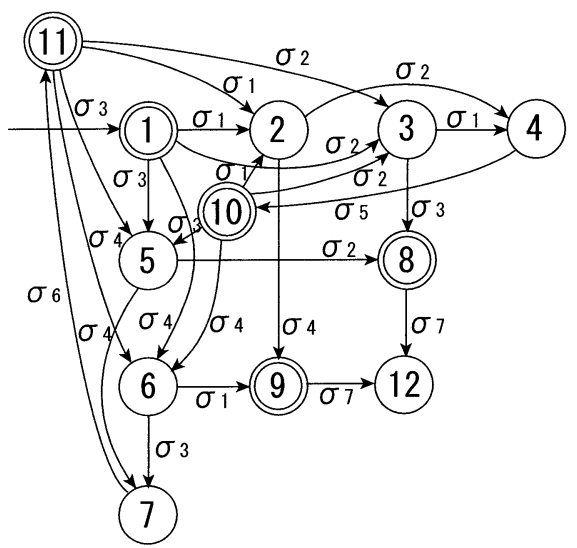

Fig. 3 Automaton of dining philosophers

Table 1 Event definition for the dining philosophers

\begin{tabular}{|c|c|}
\hline Event & Description \\
\hline \hline$\sigma_{1}$ & $P_{1}$ picks up $F_{1}$ from the table \\
\hline$\sigma_{2}$ & $P_{1}$ picks up $F_{2}$ from the table \\
\hline$\sigma_{3}$ & $P_{2}$ picks up $F_{1}$ from the table \\
\hline$\sigma_{4}$ & $P_{2}$ picks up $F_{2}$ from the table \\
\hline$\sigma_{5}$ & $P_{1}$ places $F_{1}, F_{2}$ on the table \\
\hline$\sigma_{6}$ & $P_{2}$ places $F_{1}, F_{2}$ on the table \\
\hline
\end{tabular}

学者を $P_{1}, P_{2}$, 各フォークを $F_{1}, F_{2}$ とすると, 各事象 $\sigma_{1}, \sigma_{2}, \ldots, \sigma_{6}$ の説明は Table 1 の通りである.ただし, $\sigma_{1}, \ldots, \sigma_{4}$ は可制御事象, $\sigma_{5}, \sigma_{6}$ は不可制御事象である. 各状態の意味は, 初期状態 1 が $P_{1}, P_{2}$ が思索, 目標状態 
10,11 は $P_{1}$ または $P_{2}$ が食事後に思索, デッドロック状 態の 8,9 は $P_{1}, P_{2}$ が 1 本ずつフォークを持つという状 態を意味している。 また，提案アルゴリズムでは，事象 コストを遷移後に受け取るとしているためデッドロック 状態では受け取ることができない。これを回避するため にシミュレーションの際に状態 12 という dummy state を追加した。これは, 不可制御事象 $\sigma_{7}$ により状態 8,9 から遷移する。

特性ベクトルは $Y=\left[\begin{array}{lllllllllll}1 & 0 & 0 & 0 & 0 & 0 & 0 & -0.5 & -0.5 & 0.1\end{array}\right]^{\mathrm{T}}$, また $\tilde{\pi}^{*}$ は各状態 $x_{i}$ において $\tilde{\pi}^{*}\left(x_{i}, \epsilon\right)=0.04$ とし, 残り の事象はすべて等確率で生起するとした。ただし， $\sigma_{7}$ の み確率 1 で生起する。これらの情報はスーパバイザにとっ ては未知であり, 学習を通じて獲得する。本例題では, 生起禁止コストは考慮していないので，スーパバイザの 受け取る報酬 $r$ は $y\left(x_{i}\right)$ で決定される。各学習率の值は, $\alpha=0.7, \beta=0.01, \lambda=0.2, \tilde{d}_{i j}$ の初期值はすべて 0.5 に 設定した. 各 $Q$ 值の初期值は 0 とし, 各 $\tilde{\pi}^{\prime}\left(x_{i}, \sigma\right)$ は, 事 象 $\sigma=\sigma_{j}\left(j \in \hat{\sigma}_{i}\right)$ と空事象 $\sigma=\epsilon$ に対し, $1 /\left(\left|\hat{\sigma}_{i}\right|+1\right)$ で 初期化した. 本論文のシミュレーションでは, 生起禁止 パターンを選択する際に $\epsilon=0.1$ とした $\epsilon$-greedy 選択を 行っている。これは, 確率 $\epsilon$ でランダムに選択した生起 禁止パターンを用い, 残りの確率で $\tilde{d}_{i j}$ に基づいた生起 禁止パターンの決定を行う。これにより，様々な生起禁 止パターンを探す余地をもったアルゴリズムとなってい る．学習は，エピソードを繰り返し経験することにより 進められる。 1 エピソードは, 初期状態から始まり， 20 ステップ経過するかデッドロック状態になることで終了 とする。

この問題の制御目標は，以下の二つである.

(1) 哲学者が状態 10,11 に到達する可能性を増やす.

(2) 哲学者が状態 8,9 に到達する可能性を減らす.

Fig. 4 は，学習により得られたスーパバイザで制御さ れた閉ループシステムであり，点線は遷移が禁止されて いることを表している．Fig. 4より，スーパバイザは，状 態 8,9 への遷移を禁止していることがわかる。これは, 文献 [4] で示されているすべての条件が既知である場合 の閉ループシステムと一致しており，スーパバイザが最

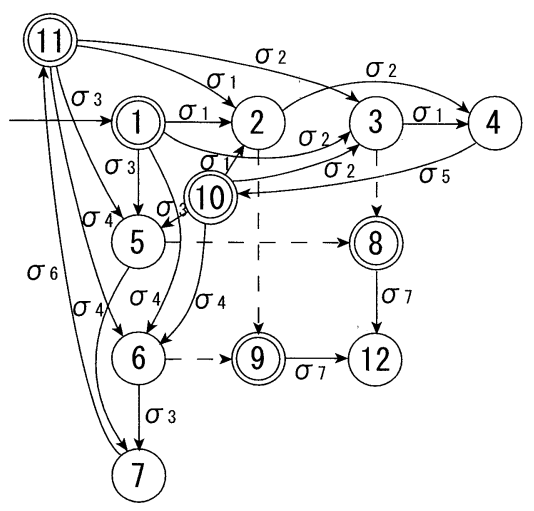

Fig. 4 Controlled plant model
適な生起禁止パターンを学習していることを示している. つぎに，100回のシミュレーションを行ったとき，各 状態でスーパバイザが学習した最大の $Q$ 值を持つ生起禁 止パターンが, Fig. 4 で表されている最適な生起禁止パ ターンとすべて合致した割合を Fig. 5 に示す. エピソー ドが進むにしたがって, 最適な生起禁止パターンを学習 していることがわかる.

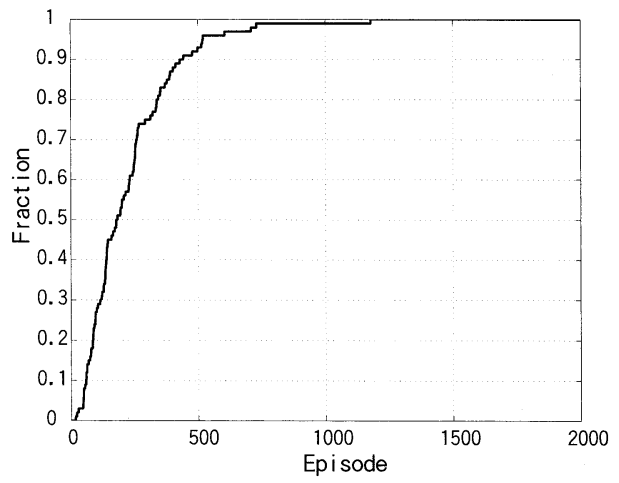

Fig. 5 Relation between the number of episodes and the fraction what the supervisor selects the optimal control pattern

文献 [4]より，すべての条件が既知である場合の初期 状態におけるパフォーマンスベクトルの理論值について, $\mu_{1}^{S}=1.7933$ であることが示されている.シミュレーショ ンでは, 約 8000 ステップ後に状態 1 の $Q$ 值がこの值に 収束していた。

\section{6. おわりに}

スーパバイザ制御の最適制御問題に着目し，Bellman 方程式における状態価值関数が，Rayらの提案する言語 測度に一致することを示した。さらに，言語測度に関し て最適となるスーパバイザを獲得するための手法として， 強化学習を用いた生起禁止パターンの学習法を提案した. 食事をする哲学者の問題に対してこのアルゴリズムを適 用し，言語測度に関して最適なスーパバイザが得られる ことを確かめた。

言語測度に関する最適スーパバイザがマルコフ決定過 程環境における Bellman 方程式の状態価值関数を求める ことにより設計できることを明らかにした。これにより， 通常の強化学習のアルゴリズムで用いられるさまざまな テクニックによる性能向上を図ることも可能になったと 考える.

今後の課題として, 事象の数が増えると, 生起禁止パ ターンの数が急激に増加するので，より効率の良いアル ゴリズムの検討が必要となる。また, 事象の生起が部分 観測となる場合への本手法の拡張も検討課題である.

\section{参考文献}

[1] C. G. Cassandras and S. Lafortune: Introduction to Discrete Event Systems, Kluwer Academic Pub. 
(1999)

[2] P. J. Ramadge and W. M. Wonham: Supervisory control of a class of discrete-event processes; SIAM J. Control Optim., Vol. 25, No. 1, pp. 206-230 (1987)

[3] W. M. Wonham and P. J. Ramadge: On the supremal controllable sublanguage of a given language; SIAM J. Control Optim., Vol. 25, No. 3, pp. 637-659 (1987)

[4] X. Wang and A. Ray: Signed real measure of regular languages; American Control Conference, Anchorage, pp. 3937-3942 (2002)

[5] X. Wang and A. Ray: A language measure for performance evaluation of discrete-event supervisory control systems; Applied Mathematical Modelling, Vol. 28, No. 9, pp. 817-833 (2004)

[6] A. Ray, J. Fu and C. Lagoa: Optimal supervisory control of finite state automata; Int. J. Control, Vol. 77, No. 12, pp. 1083-1100 (2004)

[7] X. Wang, J. Fu, P. Lee and A. Ray: Robot behavioral selection using discrete event language measure; American Control Conference, pp. 5126-5131 (2004)

[8] Y. Brave and M. Heymann: On optimal attraction of discrete-event processes; Inform. Sciences, Vol. 67, pp. 245-276 (1993)

[9] R. Kumar and V. K. Garg: Optimal supervisory control of discrete event dynamical systems; SIAM J. Control Optim., Vol. 33, No. 2, pp. 419-439 (1995)

[10] H. Marchand, O. Boivineau and S. Lafortune: Optimal control of discrete event systems under partial observation; Proc. of the 40th IEEE Conference on Decision and Control, pp. 2335-2340 (2001)

[11] R. Sengupta and S. Lafortune: An optimal control theory for discrete event systems; SIAM J. Control Optim., Vol. 36, No. 2, pp. 488-541 (1998)

[12] 山㟝, 潮: 強化学習を用いた離散事象システムのスーパバ イザ制御; システム制御情報学会論文誌, Vol. 16, No. 3, pp. 118-124 (2003)

[13] T. Yamasaki and T. Ushio: Supervisory control of partially observed discrete event systems based on a reinforcement learning; Proc. of International Conference on Systems, Man, and Cybernetics, pp. 2956-
$2961(2003)$

[14] T. Yamasaki and T. Ushio: Decentralized supervisory control of discrete event systems based on reinforcement learning; Proc. of 10th IFAC/IFORS/ IMACS/IFIP Symposium on Large Scale Systems: Theory and Application, pp. 379-384 (2004)

[15] R. S. Suton and A. G. Barto: Reinforcement Learning, MIT Press (1998) 